Development Organisation.

Attention was also drawn in Geneva to the damaging restrictive practices contained in a dusty old piece of international law-the Paris Convention of 1883-which defined industrial property rights for a world very different from that of today. With its regulations tivity techniques which would condemn the developing countries to a permaon patents and like matters often work- ing to the detriment of developing countries, they and the workers' group called for this Convention to be "drastically revised."

In its final report, the World Employment Conference endeavoured to strike a balance between the need for tcchnologies which will generate the maximum possible growth of employment and the avoidance of low-producnently inferior role in the world economy. In practice, the technology choices of developing countries tend towards the capital-intensive end of the spectrum where work places will be few and far between for the one thousand million job-hunters in the year 2000. The danger is that what the report calls a "strategy of equilibrium" will be taken by most governments as an endorsement of whatever their policy now happens to be.

\title{
USSR
}

\section{Down Georgia way}

Wendy Barnaby, recently in the Georgian SSR, describes some of the scientific work going on there

IT takes two and a half hours to fly from Moscow to Tbilisi, the capital of the Georgian Soviet Socialist Republic. In this sunny space between the Black and Caspian Seas, the amount of human effort devoted to science depends on how successfully it-and everything else-competes with the five million Georgians' favourite occupation: the ceremonious consumption of their excellent local wines. And, as a few days spent with the Georgian Academy of Sciences shows, science is coming out of the competition extraordinarily well.

Astrophysical astronomy is concentrated in the southern republics of the Soviet Union, where the weather permits good observation. The air is especially clear on Mt Kanobili $(1,700$ $\mathrm{m}), 250 \mathrm{~km}$ from Tbilisi and only about $40 \mathrm{~km}$ from the Turkish border. Spread throughout the trees on the mountain top is the Academy's Abastumani Observatory, founded in 1937 as the first experimental mountain astro-physical observatory in the USSR. Work here is mainly concerned with galactic research. The resident scientists (including many women) study stars' spectra and classify them in order to examine the distribution of the stars according to their age and chemical composition. From such a distribution investigations are made of the structure of our galaxy. So far, about 100,000 stars have been classified, using a telescope whose diameter is the third largest in the world. During their last 20 years' research, the astronomers have discovered two of the 150 Supernova stars as well as about 100 emission stars.

The observatory's stellar telescope has a diameter of $125 \mathrm{~cm}$ and is the biggest fully automatic one in the USSR. The computer attached to it processes 1 million bits of information a second, and its memory stores 32,000 bits. Observations, which can be made on 160-170 nights a year, are mainly for determining the stars' chemical composition, physical properties and light variation. The solar telescope is used more frequently: generally on 260 days a year. Through studying the physical properties of solar flares and sun spots, the astronomers hope to be able to predict solar activity. They also do photometric and spectroscopic studies of optic radiation of the sun's atmosphere, and of radio emission at $220 \mathrm{MHz}$. The resulting data is shared under the Solar Service Programme.

Back at Tbilisi, the Underground Gravimetric Laboratory of the Academy's Institute of Geophysics is the centre of the Communist countries' cooperative efforts to study earth tides. Half burrowed into a hill overlooking the city, the laboratory is accumulating data which it is hoped will lead to the prediction of earthquakes. In tunnels leading off from basement passages, two double-component quartz extensometers composed of welded quartz tubes have been fixed so that their movements will reflect the tidal and secular deformations of the earth's crust, enabling these to be observed. Any movement is recorded photoelectrically, with a reading of $1 \mathrm{~mm}$ on the tape corresponding to a change of 0.1 micron on the ground. Between 1965 and 1972 , the value of the recorded drift of one extensometer in the direction $\mathrm{N} 60^{\circ} \mathrm{E}$ was $11.9 \times 10^{-6}$. The value of deformation in the direction $\mathrm{N} 30^{\circ} \mathrm{W}$ between 1966 and 1972 was $14.7 \times 10^{-8}$.

Further down the passages, tiltmeters on basalt bases record changes in N-S and $\mathrm{E}-\mathrm{W}$ directions. The instruments are housed in a chamber $60 \mathrm{~m}$ under the ground, where the diurnal temperature variation does not exceed $0.005^{\circ} \mathrm{C}$. From 1967 to 1972 , the total drift in the N-S direction was 0.4 microns, and that in the E-W direction was 3.0 microns. The readings from both tiltmeters and extensometers are interpreted by the laboratory's staff as evidence of the existenc of secular movements of the earth's surface. So far there has been no success in using this knowledge to predict earthquakes : neither at this laboratory, nor at a new seismic station nearby, where equipment is being installed for the measurement of seismic waves from local and distant events. (Incidentally, the scientists at the station claimed that their research will enable them to locate and identify nuclear explosions in rock and in the Northern Hemisphere down to less than 10 kilotons. If the station were integrated into an international net, it could presumably contribute to the verification of any future comprehensive test ban treaty).

The Gravimetric Laboratory's methods are also being used to measure the earth's movements at a hydroelectric dam under construction about $50 \mathrm{~km}$ from Tbilisi. The plant, which will be completed in 1978 , will have a capacity of $130 \mathrm{MW}$. Its artificial lake will hold 500 million cubic metres which will irrigate 45,000 hectares of land and supply drinking water to Tbilisi and its industrial area for 80 100 years.

Another of the laboratory's activities is the suppression of hail which threatens to destroy large parts of Georgia's grape crops every year. In 1974, 20,000 rockets containing silver iodide were launched from 34 automaticallysynchronised firing points to save 360,000 hectares. Radar was used to detect clouds up to 15,000 metres, and results were good if the approaching front was narrow but not so good if it was broad. Because silver iodide is very toxic and expensive, research is being done into substitutes-ice with chemicals, for example.

In addition to coping with a heavy load of scientific work, a number of Academicians-including the VicePresident-represent Georgia in the Supreme Soviet of the USSR. This involves them in political activity to a degree extremely rare for active scientists in the West. Such involvement undoubtedly has its good and bad sides, but inasmuch as it contributes to the activism of science it seems a pity that Western scientists do not become more politically involved in their own societies. 